\section{U.S. National Academy of Sciences Awards}

IT is announced by Science Service that the Elliot Medal for 1931 has been awarded to the late Prof. Davidson Black, of the U.S. National Academy of Sciences, for his researches on the skull of Peking man. The medal and honorarium is awarded annually for work on zoology or palæontology. The first award of the Charles Doolittle Walcott Medal and honorarium of 1,350 dollars of the Academy has been made to Dr. David White, of the U.S. Geological Survey, in recognition of his work on the pre-Cambrian algæ of the Grand Canyon of Arizona, which are among the very oldest of plant fossils. Other awards just announced are: Agassiz Medal, to Dr. Bjorn HellandHansen, of the Geophysical Institute, Bergen, Norway; Public Welfare Medal, to Dr. David Fairchild, formerly of the U.S. Department of Agriculture ; and the Elliot Medal and honorarium of 200 dollars for 1930, to Dr. G. E. Coghill, Wistar Institute of Anatomy and Biology, Philadelphia.

\section{U.S. National Academy of Sciences}

AT the meeting of the National Academy of Sciences held in Washington on April 23-25, the following elections were made. Members : Prof. V. Bush, professor of electrical engineering and vicepresident of the Massachusetts Institute of Technology ; Prof. H. S. Gasser, professor of physiology, Cornell University Medical College, New York; Prof. E. N. Harvey, professor of physiology, Princeton University; Prof. D. R. Hoagland, professor of plant nutrition, University of California; Prof. E. O. Lawrence, professor of physics, University of California; Prof. J. F. Norris, director of the research laboratory of organic chemistry, Massachusetts Institute of Technology; Dr. J. H. Northrop, biochemistry, member of the Rockefeller Institute; Prof. C. Palache, professor of mineralogy, Harvard University ; Dr. T. M. Rivers, pathology, member of the Rockefeller Institute; Prof. E. Sapir, Sterling professor of anthropology and linguistics, Yale University ; Dr. E. C. Stakman, plant pathologist, U.S. Department of Agriculture ; Prof. H. S. Vandiver, associate professor of mathematics, University of Texas ; Prof. N. Wiener, professor of mathematics, Massachusetts Institute of Technology; Prof. S. Wright, professor of zoology, University of Chicago. Foreign associates: Prof. V. F. K. Bjerknes, professor of meteorology in the University of Oslo; Prof. Robert Robinson, Waynflete professor of chemistry in the University of Oxford.

\section{Native Lands in Kenya}

ANY apprehension that the rights and sentiments of the Kenya natives in the matter of their lands are likely to be endangered by future government action, taken without full knowledge, should be allayed by the Report of the Kenya Land Commission which has now been issued with a White Paper stating the views of the Government. (Cmd. 4556, $11 s$. and Cmd. 4580, 2d.) The appropriation of a part of the native reserve in the development of the Kakamega gold-fields, notwithstanding arguments advanced in justification, aroused a feeling of uneasiness and a fear lest any policy of development, however short-sighted, might in future be allowed to override obligations or measures framed to preserve the integrity and ultimate stability of native society. The report of the Commission and the supporting body of evidence, which examine native claims relating to the land in detail, tribe by tribe, provide a permanent record defining the position in native land tenure, and at the same time, by recommending that the Native Lands Board no longer exercise administrative functions but be devoted entirely to the office of protection-a recommendation accepted by the Government-ensures that, given a satisfactory constitution of the Board, the interests of the native as determined in this combination of Domesday and Magna Charta, shall not go by default. Further, the Board is given the power of veto over leases of land exceeding ten acres in extent. The principle of leasing is to take the place of exclusion of land from the reserve and exchange, the land thereby remaining part of the reserve. This, together with the requirement that native opinion shall be consulted, is not only in harmony with the sentiment and practice of the natives, but also avoids the more objectionable features which have hitherto appeared in land development.

THE Commission does not confine itself to present grievances and difficulties, but has a clear view of the future development of the native. Not only are 1,474 sq. miles added to the native reserve in satisfaction of present claims, but also a further area, totalling in all more than 2,000 sq. miles, is to be set aside to meet present and future economic requirements. In part of this additional area the system of tenure is to be more elastic than in the native reserve. Tribal tenure will no longer be the only system, and the tendency of the native towards other forms of the economic unit will be recognised. In other words, the native will be afforded an opportunity to habituate himself to a form of tenure more nearly in accord with the economy of European civilisation. It is also suggested-though this recommendation will not be adopted until it has been considered by the local legislature-that certain reserve boundaries should be eliminated or modified to permit intertribal expansion and interpenetration. The trend in these recommendations towards a modification of native culture is carried further in the stress laid on the necessity for a less wasteful use of the land and the references to proposals for restriction of the excessive number of cattle now carried. As cattle form the currency and wealth of the native, should these proposals be given effect, he must needs accustom himself to some new form of wealth. Up to the present, the increased resources which civilisation has brought to the native, in so far as they are not absorbed in the acquisition of an excessive number of cattle, would appear mainly to have been expended wastefully. On the whole, it may be said that in its outlook on the future, the report, recognising that the native is entering upon 
a period of transition in which traditional culture must suffer modification, has suggested lines on which development will bring about the least dislocation and can most effectively be brought under an enlightened control.

\section{Petrol from Coal}

THOSE who have maintained that the successful production of petrol from coal would prove of incalculable benefit to our long languishing coal industry will derive much satisfaction from a reply given in the House of Commons on May 17. $\mathrm{Mr}$. Mitcheson asked the Secretary for Mines if he could furnish an estimate of the increased consumption of coal in Great Britain which has resulted from the imposition of a duty on fuel oil. The Secretary for Mines (Mr. Ernest Brown), in reply, said : "Official information is not available. But a short time ago I received a deputation from the Coal Utilisation Council and other bodies, which furnished detailed information, collected by various trade organisations. This showed that, in terms of coal, there had been conversions from oil to coal and coal products, and business retained which it was stated would, but for the tax, have been lost to home produced fuels, representing an annual rate of consumption of over 600,000 tons."

\section{Sexual Selection in the Pheasant}

THE Zoological Society of London has just received a noteworthy addition to its Gardens in a pair of Rheinhardt's Argus pheasants (Rheinhardtius ocellata), for this is one of the rarest of the pheasant tribe. Those who are interested in problems of sexual selection will find these birds well worth thoughtful study, for they present a striking contrast with the commoner and better known Argus pheasant (Argusianus). This bird occupied a prominent place in Darwin's "Descent of Man", on account of the enormous development of the secondary wingfeathers, the like of which is seen in no other bird. These feathers are also remarkable for their ornamentation, which consists of a series of ocelli which, as Darwin pointed out, when they are displayed in the courtship attitude, look like a series of balls lying within a cup-shaped socket, while the primaries are marked by a pattern of indescribable beauty. The wings of Rheinhardt's pheasant lack any form of ornament, and in shape conform to the usual type of pheasant wing. The tail feathers, however, are prodigiously long and marked by a pattern of considerable beauty. This striking difference in the secondary sexual characters in these two birds is puzzling. Nothing seems to be known of the nature of the display of Rheinhardtius in its amorous moods. It is to be hoped, therefore, that the new arrivals will greatly enlighten us on this point. The display of the wings in the Argus pheasant is unique, the two wings being widely spread so as to form an enormous circular fan completely concealing the rest of the body. It affords an unanswerable argument to those who hold that birds in 'display' are not conscious of their finery.

\section{Mathematics and Cosmic Research}

IN a lecture entitled "World-Gravitation by Kinematic Methods" given by Prof. E. A. Milne before the London Mathematical Society on May 17, his hearers had the thrilling experience of seeing a possible model of the universe constructed before their eyes by a simple, but wholly brilliant, applica. tion of apparently trivial mathematical methods. Starting with Newtonian time, Prof. Milne envisaged the behaviour of a set of particles of which the description given by an observer placed at any one of them would be the same as that given by an observer placed at any other. The hypothesis leads to certain functional and differential equations from the solution of which Prof. Milne deduced a statistical model of extreme elegance. The astonishing result was obtained that in a given volume of the observer's space there are particles the velocity of which is arbitrarily near that of light. On this, Prof. Milne showed how a theory of cosmic rays and obscuring matter in interstellar space could be based. The striking simplicity of the method and the far-reaching character of its interpretations open up a new vista of possibilities for cosmic research.

\section{Demonstration of Television}

ON May 15 a demonstration of the use of the cathode ray tube in television reception was given before the Electrical Association for Women at the showrooms of the Edison Swan Electric Co. Ltd., London. After a very clear and non-technical exposition of the basic principles had been given, the B.B.C. 30-line transmission was received. The results obtained suggested that the cathode ray tube is capable of giving as good an image as the limitations of the transmission will permit. There was very little flicker, owing to the large afterglow of the fluorescent material of the screen. The latter was of the usual type giving a green image; the use of white fluorescent screens is not considered desirable at the low picture frequency at present in use, as the afterglow with these is much less. The scanning is accomplished by means of two small oscillators giving voltages of saw-tooth wave-form and appropriate frequencies which are applied to the two pairs of deflecting plates; the incoming signals hold these oscillators in synchronism with the transmitter and also modulate the intensity of the electron beam. Difficulty was experienced in keeping the picture steady during the demonstration, but this was attributable to the exceptionally bad local reception conditions. It was stated that in normal circumstances the controls need not be touched during the whole transmission period of half an hour. The advantages claimed for the cathode ray tube are that it is noiseless, that signals of good headphone strength only are required to operate it, and that by the alteration of a few minor circuit components it can be easily adapted to suit transmissions of different numbers of lines and pieture ratios. The last point is important in view of the uncertainty in the future development of television. Suitable tubes can now be marketed at six guineas and this price could be 